\title{
Spectroradiometry in PV: how inter-laboratory comparison may improve measurement accuracy
}

Pravettoni, Mauro; Galleano, Roberto ; Zaaiman, Willem; Alvarez, Diego Alonso; Belluardo, Giorgio; Betts, Tom R.; Bogeat, Jose Antonio; Cole, lan R. ; Drobisch, Alexander; Ferretti, Nicoletta

Total number of authors:

26

Published in:

Proceedings of 7th World Conference on Photovoltaic Energy Conversion

Link to article, DOI:

10.1109/PVSC.2018.8547975

Publication date:

2018

Document Version

Peer reviewed version

Link back to DTU Orbit

Citation (APA):

Pravettoni, M., Galleano, R., Zaaiman, W., Alvarez, D. A., Belluardo, G., Betts, T. R., Bogeat, J. A., Cole, I. R., Drobisch, A., Ferretti, N., Friedrich, D., Fucci, R., Gómez, T. J., Graditi, G., Halwachs, M., Haverkamp, E.,

Minuto, A., Phinikarides, A., Plag, F., ... Vilaplana, J. M. (2018). Spectroradiometry in PV: how inter-laboratory comparison may improve measurement accuracy. In Proceedings of 7th World Conference on Photovoltaic Energy Conversion IEEE. https://doi.org/10.1109/PVSC.2018.8547975

\section{General rights}

Copyright and moral rights for the publications made accessible in the public portal are retained by the authors and/or other copyright owners and it is a condition of accessing publications that users recognise and abide by the legal requirements associated with these rights.

- Users may download and print one copy of any publication from the public portal for the purpose of private study or research.

- You may not further distribute the material or use it for any profit-making activity or commercial gain

- You may freely distribute the URL identifying the publication in the public portal 


\title{
Spectroradiometry in PV: how inter-laboratory comparison may improve measurement accuracy
}

\author{
Mauro Pravettoni ${ }^{1}$, Roberto Galleano ${ }^{2}$, Willem Zaaiman ${ }^{2}$, Diego Alonso Alvarez ${ }^{3}$, Giorgio Belluardo ${ }^{4}$, \\ Tom R. Betts ${ }^{5}$, Jose Antonio Bogeat ${ }^{6}$, Ian R. Cole ${ }^{5}$, Alexander Drobisch ${ }^{7}$, Nicoletta Ferretti ${ }^{7}$, \\ Dirk Friedrich $^{8}$, Raffaele Fucci ${ }^{9}$, Trinidad J. Gómez ${ }^{10}$, Giorgio Graditi ${ }^{9}$, Martin Halwachs ${ }^{11}$, \\ Erik Haverkamp ${ }^{12}$, Alessandro Minuto ${ }^{13}$, Alexandros Phinikarides ${ }^{14}$, Fabian Plag ${ }^{8}$, Marcus Rennhofer ${ }^{11}$, \\ Ruben Roldan Molinero ${ }^{15}$, Nicholas Riedel ${ }^{16}$, Marios Theristis ${ }^{14}$, Anders Thorseth ${ }^{16}$, Gianluca Timò ${ }^{13}$, \\ Jose Manuel Vilaplana ${ }^{6}$ \\ ${ }^{1}$ Solar Energy Research Institute of Singapore, National University of Singapore, 117574 Singapore \\ ${ }^{2}$ European Commission, Joint Research Centre, 21027 Ispra, Italy \\ ${ }^{3}$ Imperial College London, South Kensington Campus, London SW7 2AZ, United Kingdom \\ ${ }^{4}$ Institute for Renewable Energy, EURAC Research, 39100 Bolzano, Italy \\ ${ }^{5}$ Loughborough University, CREST, Leicestershire LE11 3TU, United Kingdom \\ ${ }^{6}$ Instituto Nacional de Técnica Aeroespacial, Dpto. de Observación de la Tierra y Atmósfera, 21130 \\ Mazagón, Huelva, Spain \\ ${ }^{7}$ PI Photovoltaik-Institut Berlin AG, 10997 Berlin, Germany \\ ${ }^{8}$ Physikalisch-Technische Bundesanstalt (PTB), 38116 Braunschweig, Germany \\ ${ }^{9}$ ENEA, Centro Ricerche di Portici, 80055 Portici, Italy \\ ${ }^{10}$ Instituto Nacional de Técnica Aeroespacial, SPASOLAB, 28850 Torrejón de Ardoz, Madrid, Spain \\ ${ }^{11}$ Austrian Institute of Technology (AIT) GmbH, 1210 Vienna, Austria \\ ${ }^{12}$ Radboud University Nijmegen, AMS, IMM, 6525 ED Nijmegen, Netherlands \\ ${ }^{13}$ Ricerca sul Sistema Energetico RSE S.p.A., 29122 Piacenza, Italy \\ ${ }^{14}$ University of Cyprus, FOSS Research Centre for Sustainable Energy, 1678 Nicosia, Cyprus \\ ${ }^{15}$ University of Applied Sciences and Arts of Southern Switzerland (SUPSI), 6952 Canobbio, Switzerland \\ ${ }^{16}$ Technical University of Denmark (DTU Fotonik) Roskilde, Denmark
}

\begin{abstract}
Spectroradiometry is a key metrological topic for accurate testing of photovoltaic (PV) devices, particularly relevant both for indoor testing on solar simulators and for outdoor testing. The relevance of accurate measurements of solar spectral irradiance has led the most renowned European solar PV test centres to take part to a series of International Spetroradiometer Intercomparisons that has taken place every year so far since 2011 in various localities in the Mediterranean Basin. This paper revisits the performance of participant laboratories and highlights the importance of inter-laboratory comparisons, showing the possible improvements in measurement reproducibility.

Index Terms - spectral irradiance, spectral mismatch, metrology, measurement uncertainty, solar simulators
\end{abstract}

\section{INTRODUCTION}

Spectroradiometry is a key metrological discipline for accurate testing of photovoltaic (PV) devices, particularly relevant both for indoor and outdoor testing, where differences between the available thermal energy and the energy usable by PV modules are relevant. Spectral irradiance is one of the three parameters according to which solar simulators are rated as per the international standard IEC 60904-9 (the other two being spatial uniformity and temporal stability). This standard has undergone its scheduled periodic revision process that will come out in early 2019 in a new edition where the spectral match will be significantly revised, extending the wavelengths limit for classification to $300-1200 \mathrm{~nm}$, from $400-1100 \mathrm{~nm}$ range of the previous edition. This change may have significant effects in the experimental practice, as has been outlined by G. Belluardo et al. [1].

Two other relevant standards for PV testing are close to publication and will stress the importance of spectral irradiance measurement for energy rating: IEC 61853 Part 3 "Energy rating of PV modules" and Part 4 "Standard reference climatic profiles". In fact, the solar spectral irradiance in the real world may differ significantly from the standard AM1.5g spectrum, depending of the geography, the geometry of the PV module installation, the varying position of the Sun in the sky during the year and weather conditions. Variations in spectral irradiance affect directly the power performance of the module, 
TABLE I

HISTORY OF PREVIOUS EDITIONS OF THE INTERNATIONAL SPECTRORADIOMETER INTERCOMPARISONS

\begin{tabular}{|c|c|c|c|c|c|c|c|c|c|}
\hline Year & Location & $\begin{array}{c}\text { Number } \\
\text { of test } \\
\text { centres }\end{array}$ & $\begin{array}{c}\text { Number of } \\
\text { instruments }\end{array}$ & $\begin{array}{c}\text { Indoorl } \\
\text { Outdoor }\end{array}$ & GNI & DNI & $\begin{array}{c}\text { Number of } \\
\text { valid days } \\
\text { (GNI) }\end{array}$ & $\begin{array}{c}\text { Number of } \\
\text { valid GNI } \\
\text { spectra }\end{array}$ & Ref. \\
\hline 2011 & Portici, Italy & 6 & 6 & Outdoor & Y & Y & 1 & 18 & {$[2]$} \\
\hline 2012 & Catania, Italy & 8 & 7 & Outdoor & Y & Y & 2 & 54 & {$[3]$} \\
\hline 2013 & $\begin{array}{c}\text { Puertollano, Spain* } \\
2014\end{array}$ & $\begin{array}{c}\text { Torrejón de Ardoz, } \\
\text { Spain }\end{array}$ & 9 & 12 & Indoor & $\begin{array}{c}\text { Xe AM0 } \\
\text { simulator }\end{array}$ & 1 & 1 & - \\
\hline 2015 & $\begin{array}{c}\text { Torrejón de Ardoz, } \\
\text { Spain }\end{array}$ & 10 & 10 & Outdoor & Y & Y & 2 & 29 & {$[4]$} \\
\hline 2016 & Trisaia, Italy & 9 & 8 & Outdoor & Y & Y & 2 & 84 & {$[1]$} \\
\hline 2017 & Catania, Italy & 8 & 10 & Outdoor & Y & Y & 2 & 50 & - \\
\hline
\end{tabular}

TABLE II

List OF PARTICIPANTS, GROUPED AS ISO/IEC ACCREDITED LABORATORIES OR NATIONAL METROLOGY INSTITUTES (IEC/NMI), UNIVERSITIES OR NON-ACCREDITED RESEARCH CENTRES (UNI/NRC), AND INDUSTRIAL PARTNERS (IND). THE INSTRUMENT IN

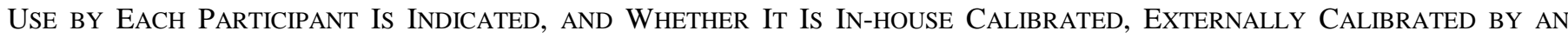
ACCREDITED LABORATORY OR CALIBRATED BY THE MANUFACTURER.

\begin{tabular}{|c|c|c|c|c|}
\hline Name (Country) & Instrument, calibration & $\begin{array}{l}\text { Range } \\
{[\mathrm{nm}]}\end{array}$ & Calibration & Group \\
\hline European Commission JRC (EU) & $\begin{array}{c}\text { Gooch\&Housego OL750 (until 2015) } \\
\text { Eko Wiser (since 2016) }\end{array}$ & $\begin{array}{l}250-2500 \\
300-1700\end{array}$ & $\begin{array}{l}\text { In-house } \\
\text { In-house }\end{array}$ & IEC/NMI \\
\hline Austrian Institute of Technology (AT) & Oceanoptics & $300-1600$ & In-house & IEC/NMI \\
\hline CIEMAT (ES) & $\begin{array}{l}\text { Avantes } \\
\text { Monolight }\end{array}$ & $\begin{array}{l}280-1430 \\
250-2500 \\
\end{array}$ & $\begin{array}{l}\text { In-house } \\
\text { In-house }\end{array}$ & UNI/NRC \\
\hline Technical University of Denmark (DK) & Eko & $300-1100$ & Manufacturer & UNI/NRC \\
\hline ENEA (IT) & Stellarnet & $310-1700$ & Externally & UNI/NRC \\
\hline ENEL (IT) & Avantes, manufacturer & $280-2570$ & Manufacturer & UNI/NRC \\
\hline $\mathrm{EKO}(\mathrm{JP}, \mathrm{NL})$ & Eko, in-house & $360-1700$ & In-house & IND \\
\hline Imperial College London (UK) & Oceanoptics & $250-1100$ & In-house & UNI/NRC \\
\hline $\begin{array}{c}\text { Instituto Nacional de Técnica } \\
\text { Aeroespacial (ES) }\end{array}$ & $\begin{array}{c}\text { Eko } \\
\text { Instrument System }\end{array}$ & $\begin{array}{l}300-1100 \\
250-1700 \\
\end{array}$ & $\begin{array}{c}\text { Manufacturer } \\
\text { In-house }\end{array}$ & IEC/NMI \\
\hline PI-Berlin (DE) & Tec5 & $300-1700$ & In-house & IEC/NMI \\
\hline PTB (DE) & Instrument System CAS 140CT & $250-2150$ & In-house & IEC/NMI \\
\hline PV-Laboratory (DE) & Instrument System CAS 140CT & $300-1100$ & Manufacturer & IEC/NMI \\
\hline Radbound University (NL) & Eko & $300-1100$ & Manufacturer & UNI/NRC \\
\hline RSE (IT) & Stellarnet & $300-1700$ & In-house & UNI/NRC \\
\hline Spectrafy (CA) & Spectrafy SolarSim-D2 + SolarSim-G & $280-2400$ & In-house & IND \\
\hline SUPSI (CH) & $\begin{array}{l}\text { Avantes (except } 2015 \text { and 2017) } \\
\text { Eko (in } 2015 \text { and 2017) }\end{array}$ & $\begin{array}{l}300-1700 \\
360-1700 \\
\end{array}$ & $\begin{array}{c}\text { In-house } \\
\text { Manufacturer }\end{array}$ & IEC/NMI \\
\hline University of Cyprus (CY) & Stellarnet & $300-1700$ & In-house & UNI/NRC \\
\hline University of Rome Tor Vergata (IT) & Eko Wiser & $360-1700$ & Manufacturer & UNI/NRC \\
\hline
\end{tabular}

depending on the spectral responsivity of the PV device. Such effect may become increasingly important in the future, if novel multi-junction PV devices will come back on the market after the disappearance of amorphous silicon (a-Si) multi-junction structures in commercial modules for residential applications, e.g. in the efficiency-promising perovskite-on-silicon tandem.

The relevance of spectral irradiance measurement may also go beyond the limits of crystalline silicon (c-Si) spectral responsivity in concentrating $\mathrm{PV}$ or space applications, where high-efficiency 3-junction to 5-junction PV cells of the III-V group are now used widely.

The importance of accurate measurements of solar spectral irradiance for such a wide range of possible applications has led most of the best renowned accredited European PV test centres to take part to a series of International Spetroradiometer Intercomparisons that has taken place every year so far since 
2011 in various localities in the Mediterranean Basin (Italy and Spain). The ever-growing number of participating laboratories is both a consequence and a key of success to the whole exercise: IEC/ISO 17025 accredited laboratories are keen on receiving confirmation of the stability and accuracy of their spectroradiometers and the same is true for the instrument manufacturers. Successful inter-laboratory comparisons can be achieved only when a conspicuous number of partners are involved.

This paper summarizes the outcomes of the last interlaboratory comparisons, trying to highlight whether improvements in measurement reproducibility can be inferred from those partners that have participated since the earliest editions. The analysis includes the full comparison of the performance evaluation of laboratories that have taken part to all intercomparisons and a figure of merit of the overall agreement between participants over the 7-year history of the exercise.

\section{Highlights Of ThE PREVIOUS EDITIONS}

Table I lists details of the previous editions of the International Spectroradiometer Intercomparison, together with the number of PV test centres involved and the number of instruments tested. Table I also reports: whether the intercomparison was measuring indoor or outdoor irradiance; and in the latter case whether Global Normal or Direct Normal Irradiance (GNI and/or DNI, respectively) spectra were measured; the total number of valid days for GNI measurements; and the total number of valid measured spectra each edition. Reference literature where detailed analysis has been published is indicated in the last column. The geographic positions of the hosting locations is shown in Fig. 1.

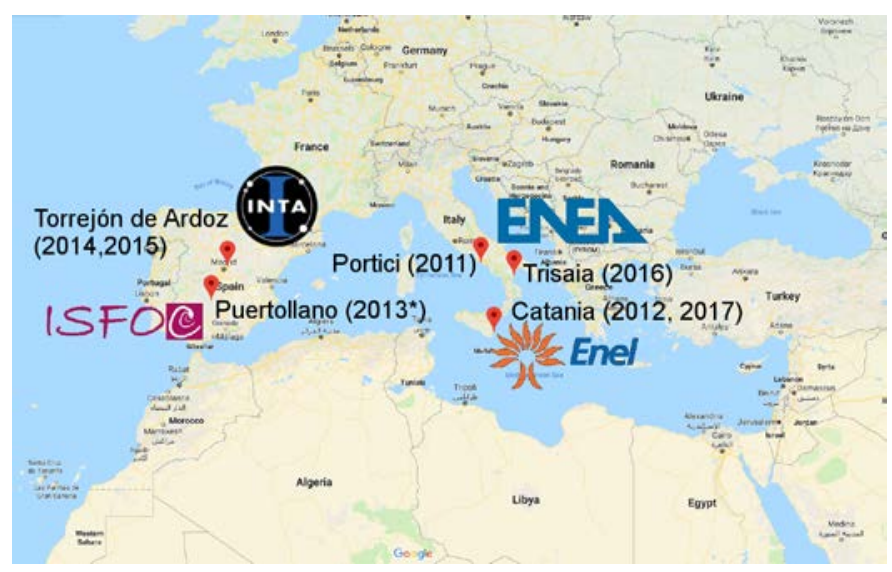

Fig. 1. Map of the seven editions of the International Spectroradiometer Intercomparison. *The 2013 edition in Puertollano, Spain, was affected by bad weather and no available measurements were recorded in that edition.
The first edition was hosted in 2011 at the Italian National Agency for New Technologies, Energy and Sustainable Economic Development (ENEA) in Portici, a town in the Metropolitan City of Naples, Southern Italy. Italy hosted also the 2012 and 2017 editions in Catania, in the island of Sicily, at the ENEL Innovation Hub, and the 2016 edition at the ENEA Trisaia Research Center, in the Southern Italian region of Basilicata.

The Mediterranean Basin offers outstanding opportunities for testing both GNI and DNI, but unlucky variable weather conditions nevertheless affected the 2013 edition, hosted at the Institute for Concentration Photovoltaics Systems (ISFOC) in Puertollano, an industrial city in the province of Ciudad Real, Castilla-La Mancha, central Spain. Spain hosted also the 2014 and 2015 editions, both at the National Institute for Aerospace Technology (INTA) in Torrejón de Ardoz, a municipality in the autonomous community of Madrid. At INTA in 2014 took place the only edition of the intercomparisons so far where indoor solar simulators were tested (continuous source, AM0 spectral irradiance), instead of the outdoor solar spectral irradiance.

Table II lists the participants of all editions, whose measurements are analysed in this work (excluding the 2013 edition, for which no results are available). The table indicates the instrument tested by each laboratory, its measurement range, and whether the instrument is in-house calibrated, externally calibrated by an accredited laboratory or calibrated by the manufacturer. Participant laboratories are also grouped as ISO/IEC accredited laboratories or National Metrology Institutes (IEC/NMI), universities or non-accredited research centres (UNI/NRC), and industrial partners (IND).

According to a confidentiality agreement, apart from European Commission JRC (also referred to as Lab A, the reference laboratory as per consensus agreement, see the next section), all the other participant laboratories have been labelled anonymously by letters from B to R. Apart from the reference laboratory, only two participants (Lab C and D) have taken part to all intercomparisons.

\section{ANALYSIS OF RESULTS}

\section{A. Technical Requirements}

In all editions, the spectroradiometers were calibrated before the event (either in-house, externally calibrated or kept under the manufacturer specifications) under the responsibility of the participant laboratory. Each participant laboratory was responsible of the competence, professional qualification and technical skills of their own staff, ensuring that measurements were taken at their own best knowledge.

During outdoor measurements (all editions except 2014), the instruments were mounted on a two-axis tracker (pointing accuracy: \pm 0.5 deg) with limited external and mutual reflections. Dedicated sessions for DNI and GNI measurements were scheduled, but in this work only results on GNI 


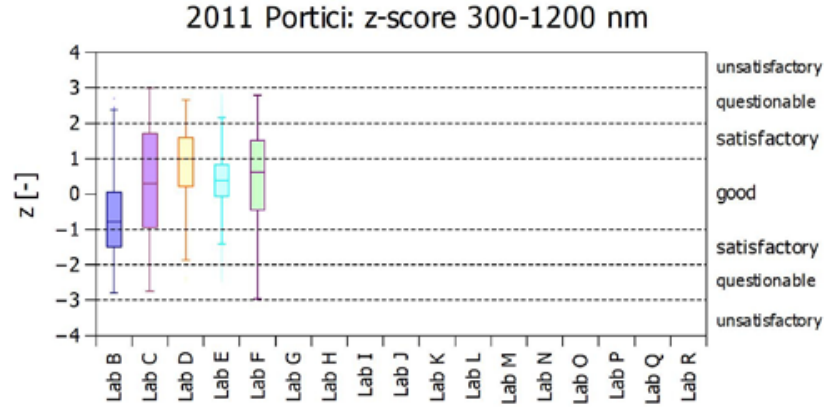

(a)

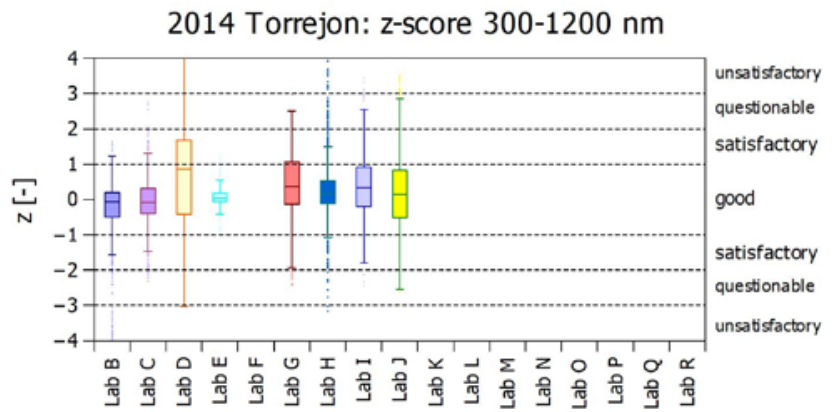

(c)

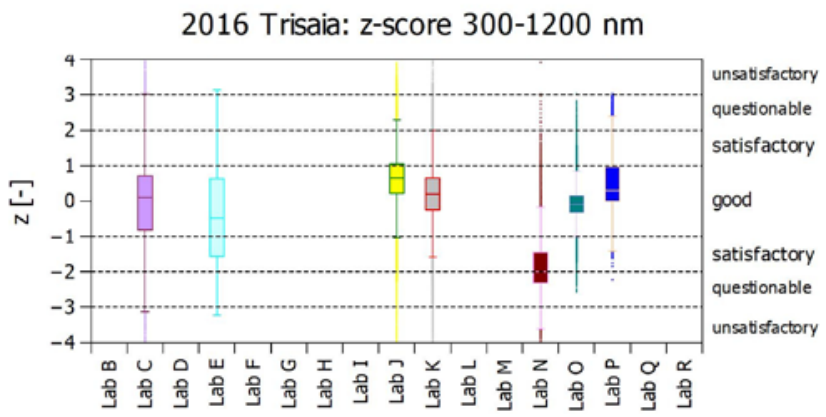

(e)

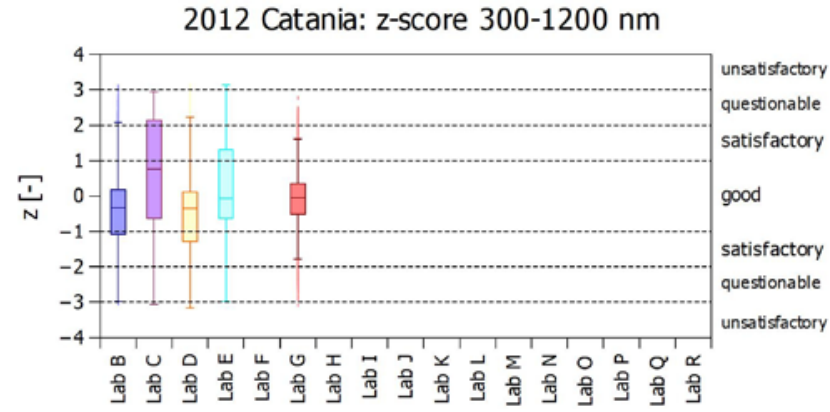

(b)

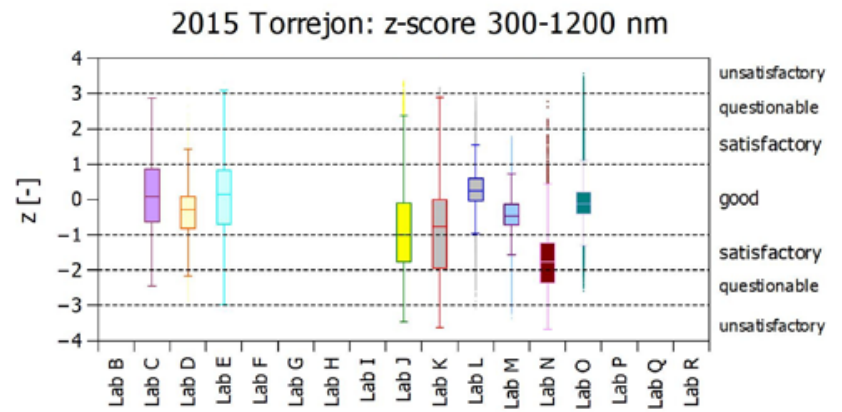

(d)

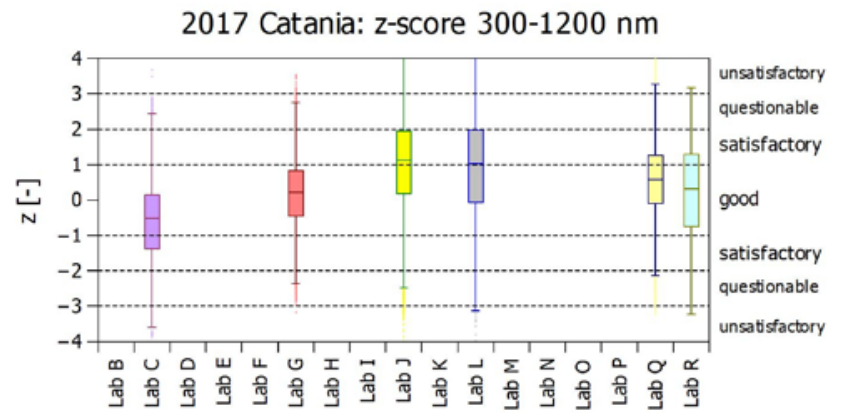

(f)

Fig. 2 Performance analysis: the box-and-whisker diagrams indicate the performance of the participating laboratories in the six past inter-laboratory comparisons. The bottom and top of each box are the $1^{\text {st }}$ and $3^{\text {rd }}$ quartiles (also referred to as interquartile range, IQR) of the $z$-score values calculated according to equation (1) at all wavelengths in the range 300-1200 $\mathrm{nm}$ (step $2 \mathrm{~nm}$ ). The whiskers extend from the ends of the box to the most distant point whose $z$-score lies within 1.5 times the IQR: $z$-values outside the whiskers are treated as outliers and are marked with dots. The band inside the box is the median ( $2^{\text {nd }}$ quartile).

measurements will be discussed. Outdoor measurements were taken continuously, approximately from 8 AM to 5 PM. The measurement sessions were carried out following a previously agreed procedure, in order to harmonize measurements acquired at different integration times (from few milliseconds up to minutes) and synchronize spectral acquisition at the start of the first measurement session.

During indoor measurements (2014 edition only), the partners tested their own spectral measurement systems under both a Xenon lamp continuous solar simulator for space PV cell calibrations and under a FEL-type standard lamp. Results presented in this paper refer to measurements of the Xe solar simulator only (AM0-like spectral irradiance at the standard $1366 \mathrm{~W} / \mathrm{m}^{2}$ total integrated irradiance on a continuous and stable flux). All instruments were tested in sequence (one measurement only) at the centre of the testing area.

In all cases, participants were given instructions on the range of measurement (the maximum allowed by each instrument) and of the resolution of the spectral irradiance required for the inter-laboratory comparison (maximum: $2 \mathrm{~nm}$ ). Measured spectra were sent as text file to the reference laboratory at the end of each intercomparison.

All outdoor measurements were performed in clear-sky conditions. The stability of spectral irradiance was assessed by stability of the total irradiance as measured by a set of cavity radiometer directly traceable to SI units (acceptance requirement: less than $\pm 1 \%$ instability during a time interval of five minutes during the spectra acquisition window). Stability 
in the 2014 indoor edition was ensured by repeated measurements by the reference instrument.

Only spectra measured under stable conditions were considered valid. Only valid spectra contribute to the performance assessment reported in this work. The statistical sample is represented by 235 outdoor valid spectral measurements per participant (nine days in total), plus one indoor spectral measurement (see Table I).

\section{B. Statistical Design And Assigned Values}

The performance analysis for the participating laboratories is performed via evaluation of the $z$-score as a function of each measured wavelength $\lambda$ of each valid measured spectral irradiance. The $z$-score is an indication of the deviation of a measurement from a reference, measured in terms of standard deviations. It is defined according to ISO/IEC 17043 [5] as

$$
z_{i}(\lambda)=\frac{E_{i}(\lambda)-E_{r e f}(\lambda)}{\sigma(\lambda)},
$$

where in our case $E_{i}(\lambda)$ and $E_{r e f}(\lambda)$ are the spectral irradiances measured in stable conditions at wavelength $\lambda$ of the $i$-th laboratory and the reference spectral irradiance (the assigned value), respectively; $\sigma(\lambda)$ is the standard deviation for the proficiency assessment. In this work $\sigma(\lambda)$ is the standard deviation between all stable measurements in a given time period and the assigned value $E_{r e f}(\lambda)$ has been chosen by consensus agreement between participant as the measured spectral irradiance by European Commission JRC (Laboratory A), based on the historical records of more stable traceability versus SI standards of the Lab A instruments.

Evaluation criteria for the $z$-score was chosen according to the following interpretation:

- $|z| \leq 1.0$ indicates a "good" performance;

- $1.0<|z| \leq 2.0$ indicates "satisfactory" performance;

- $2.0<|z|<3.0$ indicates a "questionable" performance;

- $|z| \geq 3.0$ indicates an "unsatisfactory" performance.

If measurement results are normally distributed, approximately $95 \%$ of results should give a $z$-score within \pm 2 and less than $1 \%$ of results are expected to give $|z| \geq 3.0$. When this happens, it is an indication of a possible measurement bias and a corrective action to investigate the origin of this bias is recommended.

\section{Performance Overview}

The box-and-whisker diagrams of Fig. 2 summarize the performance of the participating laboratories in the six past inter-laboratory comparisons in terms of $z$-scores calculated according to equation (2). The bottom and top of each box are the $1^{\text {st }}$ and $3^{\text {rd }}$ quartiles (also referred to as interquartile range, IQR) of the $z$-score values at all wavelengths in the range 300$1200 \mathrm{~nm}$ (step $2 \mathrm{~nm}$ ). The whiskers extend from the ends of the box to the most distant point whose z-score lies within 1.5 times the IQR: $z$-values outside the whiskers are treated as outliers and are marked with dots. The band inside the box is the median ( $2^{\text {nd }}$ quartile).

The interpretation of Fig. 2 varies, whether the attention is focused on the boxes (the IQR) or on the whiskers. Focus on the IQR indicates that in more than $90 \%$ of the cases the central half of the measurements of the laboratories was "satisfactory", and $50 \%$ of the cases it was indeed "good". This result is only marginally enhanced by the fact that in 2014, when measurements were performed indoors (in a temperaturecontrolled environment and more stable source), the performance of the participating laboratories is generally better than in the other years.

The overall result seems less positive if the focus is on the whiskers rather than on the boxes, taking therefore into account 1.5 times the IQR, i.e. approximately $95 \%$ of the measurements. In this case, while only one third of the laboratories shows performances fully within the "satisfactory" range (of which nearly $12 \%$ shows "good" performances), still only $15 \%$ of the participants over the years report measurements rated as "unsatisfactory".

\section{DISCUSSION}

\section{A. Trend Lines On Selected Laboratories}

More detailed analysis can be performed on selected laboratories. Laboratory $\mathrm{C}$ is the only participants having measured GNI in all inter-laboratory comparisons. A positive trend can be observed in the dispersion of its z-scores from 2011 to 2014, where in indoor measurements the performance was remarkable. Further changes in the instrument may have affected further improvements, even though the performance of the IQR overall remains "good" since 2014, with a minor deviation in 2017.

Laboratory $\mathrm{G}$ is one of the instrument manufacturers and the performance has been always remarkable with no observable trend out of statistical variability. "Good" performance is observed also for Laboratory M, a National Metrology Institute, whose outstanding results are reported only for the 2015 edition in Torrejón.

A general decrease in the width of the IQR can be observed on almost all laboratories in two subsequent years of participation, suggesting the importance of the inter-laboratory comparison as a useful tool to improve measurement accuracy. The exception was Lab E from 2011 to 2012, whose shortcoming was subject of corrective action and the instrument was set for recalibration.

\section{B. Impact On Photovoltaic Device Testing}

Evaluating the impact on the spectral mismatch factor (MMF, [7]) for the calibration of a c-Si reference cell, shows a decrease of MMF dispersion from 2\% (results from Portici 2011) to less than $1 \%$ (results from Torrejón 2015) for selected laboratories. 
The MMF for a typical 3-junction (InGaP/InGaAs/Ge) cell was calculated for indoor measurements of the 2014 edition, where Fig. 2 has highlighted the lowest dispersion in $z$-score values among participants. MMF was calculated for all measured spectra, against the standard spectrum and a c-Si reference cell for each of the three junctions, according to the standard procedure [7]. Using a c-Si reference cell rather than a filtered reference cell highlights the spectral mismatch. Tab. III summarizes the fraction of measured spectra giving calculated MMF values in agreement with the one calculated from Lab A reference instrument within $1 \%, 2 \%, 5 \%$ and $10 \%$ difference, over all the measured spectra. The result highlights the higher reliability of the measured spectra in the UV and visible region (300-700 nm, where the InGaP top junction responds) and the challenges in the infrared region (700-900 nm for InGaAs middle junction spectral responsivity and the extended wavelength band of 900-1800 nm for Ge bottom junction).

\section{TABLE III}

DIFFERENCES IN THE CALCULATED MMF VALUES FOR THE THREE JUNCTIONS OF A TYPICAL COMMERCIAL 3-JUNCTION INGAP/INGAAS/GE PV CELL, WITH RESPECT TO THE MMF CALCULATED FROM THE SPECTRUM MEASURED BY LAB A REFERENCE INSTRUMENT (TORREJÓN, 2014).

\begin{tabular}{|c|c|c|c|c|c|}
\hline & $<\mathbf{1 \%}$ & $<\mathbf{2 \%}$ & $<\mathbf{5 \%}$ & $<\mathbf{1 0} \%$ & $>\mathbf{1 0} \%$ \\
\hline Top & $38 \%$ & $50 \%$ & $81 \%$ & $94 \%$ & $6 \%$ \\
\hline Middle & $19 \%$ & $56 \%$ & $75 \%$ & $75 \%$ & $25 \%$ \\
\hline Bottom & $6 \%$ & $12 \%$ & $25 \%$ & $26 \%$ & $44 \%$ \\
\hline
\end{tabular}

\section{Further Activities}

The $z$-score analysed in this work is a useful tool to highlight outlying performances with respect to the average performance and to the assigned reference measurement. To account for measurement uncertainty another parameter is typically used in proficiency testing: the $E_{n}$ number [5]. In the future interlaboratory comparisons the participants should include information on their measurement uncertainties and a more complete performance evaluation may be performed.

Section B above gave a first impression on the impact that poor reliability in spectral measurement may have in the electrical characterization of multi-junction PV devices. Following the expected renowned interest in these structures also for non-concentrating PV and large-scale applications, it may be beneficial to investigate more on the topic, starting with a more granular performance analysis that may differentiate between the UV, the visible and the NIR measurement range.

Another innovative area that will become more and more commercially relevant in the coming years is bifacial PV modules. Bifacial modules convert into electricity also the portion of light diffused to their rear side (the albedo): spectral measurement of the albedo and related challenges may also be subject of novel investigation in the incoming future International Spectroradiometer Intercomparisons.

\section{CONCLUSIONS}

Measurement inter-laboratory comparison is a useful scheme for controlling the performance of measurement equipment and is often developed in the form of proficiency testing. This work gave a summary of the spectroradiometric measurement intercomparison campaigns that have been conducted so far since 2011 at a yearly basis between PV test centres, metrology institutes and spectroradiometer manufacturers.

The results represent a useful insight in the challenge to improve spectral measurement reproducibility that is of pivotal importance for both outdoor measurement of the solar spectrum and for indoor characterization of PV devices.

\section{ACKNOWLEDGEMENTS}

The authors would like to acknowledge the hospitality of the centres where the inter-laboratory comparisons have taken place. They are also grateful to the support of both ReRa Solutions and of the European Joint Research Centre for their support in the organization. Warm gratitude goes also to all researchers who have added their precious contribution in the past, whose names could not be included in the list of authors.

\section{REFERENCES}

[1] G. Belluardo, R. Galleano, W. Zaaiman, M. Pravettoni, M. Halwachs, R. Fucci, A. Drobisch, M. Friederichs, E. Haverkamp, A. Phinikarides, and G. Friesen, "Extending the Spectrum Characterization of Solar Simulators from $300 \mathrm{~nm}$ to $1200 \mathrm{~nm}$ : Challenges on Spectral Measurements in the UV and NIR", Proc. $33^{\text {rd }}$ European Photovoltaic Solar Energy Conference and Exhibition, 1359-1363, 2017.

[2] R. Galleano, W. Zaaiman, A. Virtuani, D. Pavanello, P. Morabito, A. Minuto, A. Spena, S. Bartocci, R. Fucci, G. Leanza, D. Fasanaro, and M. Catena, "Intercomparison campaign of spectroradiometers for a correct estimation of solar spectral irradiance: results and potential impact on photovoltaic devices calibration", Prog. Photovolt: Res. Appl.22 1128-1137, 2014.

[3] R. Galleano, W. Zaaiman, C. Strati, S. Bartocci, M. Pravettoni, M. Marzoli, R. Fucci, G. Leanza, G. Timò, A. Minuto, M. Catena, F. Aleo, S. Takagi, A. Akiyama, R. Nuez, and G. Belluardo, "Second international spectroradiometer intercomparison: results and impact on PV device calibration", Prog. Photovolt: Res. Appl. 23, 929-938, 2015.

[4] R. Galleano, W. Zaaiman, D. Alonso-Alvarez, A. Minuto, N. Ferretti, R. Fucci, M. Pravettoni, M. Halwachs, M. Friederichs, F. Plag, D. Friedrich, and E. Haverkamp, "Results of the Fifth International Spectroradiometer Comparison for Improved Solar Spectral Irradiance Measurements and Related Impact on Reference Solar Cell Calibration", IEEE J. Photovolt. 6(6), 15871597, 2016.

[5] ISO/IEC 17043:2010 “Conformity Assessment - General requirements for proficiency testing”.

[6] ISO/IEC 60904-3: "Photovoltaic devices. Part3: Measurement principles for terrestrial photovoltaics solar devices with reference spectral irradiance data” (Ed. 3), 2016.

[7] ISO/IEC 60904-8: "Photovoltaic devices. Part 7: Computation of the spectral mismatch correction for measurements of photovoltaic devices” (Ed. 3), 2008 